\title{
Today's Entrepreneurs Can Inform Tomorrow's Research
}

\author{
Gary Dushnitsky (London Business School) \\ Sharon Matusik (University of Colorado)
}

\section{KEYWORDS: Entrepreneurship, Research Methods.}

Consider that only as far back as the year 2000, starting a business meant writing a business plan, buying facilities or equipment, and courting traditional investors such as banks or venture capital firms. Today it may include those things, but entrepreneurs are also comfortable with experimenting, pivoting and building "minimum viable products," or MVPs. In summary, the past few decades have brought seismic shifts that have transformed the business world. Technology, crowdfunding, the "Lean Startup" movement and nearly unlimited access to information are just a few of them. These changes are upending how companies are hatched and managed, how they develop and test ideas in the marketplace, and how they approach scaling and growth. But what do these changes mean for the future of entrepreneurship research?

We explored this question in a recent article published in the Strategic Entrepreneurship Journal (https://onlinelibrary.wiley.com/doi/abs/10.1002/sej.132 4) . In the article, we reviewed classic research on entrepreneurship and compared it with what today's business people are saying about their own realities and challenges. This approach provides fertile ground for entrepreneurship scholars and practitioners alike. It highlights the opportunity to revisit well-established frameworks and assumptions we often take for granted. Such investigation can prove fruitful in one of two ways. On the one hand, it could be that embracing new realities and patterns will yield new theoretical frameworks. On the other hand, it may provide fresh evidence that existing theory is still sound.

The purpose of our article is to stir up a dialogue between a theory-led discussion and practitioner-led deliberations. To stimulate such conversations, we looked at existing research in three broad areas that are important to entrepreneurs: the origin of entrepreneurial opportunities, organizing and scaling, and resource acquisition. Our sense of how entrepreneurship has evolved was informed by our own extensive work with entrepreneurs, financiers and others. We also learned from a recent practitioner-led discussion held in Boulder, Colorado that included participants from leading entrepreneurial organizations, including TechStars, Oracle, the Foundry Group and Havenly, as well as leading economic development officials.

\section{The Origin of Entrepreneurial Opportunities}

A century ago, motivated by the observation that access to information is not equal, Schumpeter argued that those who possess knowledge and insights that nobody else has can build on that knowledge to create groundbreaking new products and ideas. That venerated piece of research - it is important to note -was written in the early $20^{\text {th }}$ century, when data and information were far less available. By 2012, as McAfee and colleagues pointed out, more data crossed the Internet every second than were stored in the entire internet 20 years earlier.

Over the decades many scholars have discussed whether opportunities are discovered or created. In an information-rich environment like today's, where it's easier for many to have access to the same information, the cognitive skills needed for developing an opportunity may have changed. Our practitioner panel seemed to echo that point. The panelists said that in the past they would evaluate entrepreneurs based on the novelty of the idea, most often a new technology. However, today entrepreneurs are most valued if they know how to craft and exploit an opportunity. "Execution is everything," one panelist said.

While the ability to seize and opportunity and run with it is important, panelists also said that they respect entrepreneurs who demonstrate strong values, a good work ethic and a commitment to social impact goals. Companies must exhibit these traits themselves to attract good people, they point out. This underscores an opportunity to shape tomorrow's research agenda. We need more evidence and rigorous research to evaluate 
the role of technical training and experience for present day entrepreneurs. And relatedly, how do such skills stand vis-à-vis the ability to seize an opportunity and act on it, and a commitment to some higher purpose?

\section{Organizing and Scaling}

For even the most promising ideas, the wrong growth strategy can be a fatal mistake. Not surprisingly, many scholars are studying growth - focusing on recruiting talent, developing roles and rules, and how a company is organized. In the past many scholars have used education and industry experience as proxies for valuable human capital.

Our panelists told us that they are looking for different skill sets to help their company grow. Today they want candidates comfortable with experimentation and scaling-up, and at home in a chaotic, rapidly evolving setting, For example, one person mentioned they might be more likely to hire an early Dropbox employee than even someone with long tenure in their own industry.

Seventy years ago, Penrose introduced the concept of organizational "slack," to capture the fact that growth is not a linear process; rather it is a slow and iterative one. In a nutshell, the idea is that a growing company may sometimes bring in more people than it currently needs, and the "slack talent" becomes the force behind experimentation, innovation and ultimate growth. However, these days many startups grow a large fraction of their critical capabilities by drawing on existing world-class capabilities that are available through Application Programming Interfaces (APIs). For instance, the ride-sharing company Lyft used API of Google Maps for navigation, Twilio for sign-up verification, and Stripe for payment. Do we fully understand the impact of the API-economy on startups' scale-up efforts and trajectories?

\section{Resource Acquisition}

Our panelists told us that in today's world of Lean Startup and crowdfunding, companies can be launched on a shoestring and without traditional financing mechanisms. This means that ventures that would not have been funded 10 years ago can more easily attract investors. And because many mechanisms allow investors to commit smaller amounts of money, more non-traditional investors are getting into the act: accelerators, micro VC funds, angel investors and individuals supporting a new venture through crowdfunding platforms.
We see the need for more research into the growing number of these non-traditional funding options. For example, research has given us a greater understanding of crowdfunding. Yet, among more than 600 scholarly works to date, the vast majority have focused largely on three big crowdfunding platforms: Kickstarter, Kiva and Prosper. But hundreds more crowdfunding platforms have emerged in the past few years across the world, and we need a broader look at how this affects access to funding for new entrepreneurs.

\section{Conclusion}

Our article illustrates some ways that entrepreneurship researchers and practitioners can learn from each other over time. High-quality research can shed light on practical problems, and "translating" findings into practical implications is an important part of the research-practice dialogue. But the bridge between research and practice must be a two-way street. To advance our body of knowledge - and help more entrepreneurs succeed in the future - scholars must keep asking them questions about how their behaviors and actions are changing. This will shape the trajectory of future scholarly research. It can either provide fresh evidence of the robustness of extant theories, or create new pathways of inquiry and yield novel frameworks.

\section{References}

Dushnitsky, G. and Matusik, S.F., 2019. A fresh look at patterns and assumptions in the field of entrepreneurship: What can we learn?. Strategic Entrepreneurship Journal, 13(4), pp.437-447.

McAfee, A., Brynjolfsson, E., Davenport, T.H., Patil, D.J. and Barton, D., 2012. Big data: the management revolution. Harvard Business Review, 90(10), pp.60-68

\section{Learn More}

Producing Research Entrepreneurs Can Use (https://eiexchange.com/content/producing-researchentrepreneurs-can-use?search=Jon\%20Eckhardt) 